\title{
Territorial inequality: an agent-based approach in modelling of social policy
}

\author{
Tatyana Novikova ${ }^{1,2^{*}}$ \\ ${ }^{1}$ Novosibirsk State University, Department of Economics, 2 Pirogova St., Novosibirsk, 630090, \\ Russian Federation \\ ${ }^{2}$ Institute of Economics and Industrial Engineering, 17 Lavrentiev Ave., Novosibirsk, 630090, \\ Russian Federation
}

\begin{abstract}
The article proposes a methodological approach for assessing the territorial inequality based on an agent-oriented spatial model. The main decisions are made in the model at the microeconomic level by households and enterprises with spatial coordinates. Then they are aggregated to the level of regions, industries and the economy as a whole. The evaluation of the indicators according to the criterion of social justice is carried out using two groups of methods: firstly, statistical, primarily the Gini coefficients (which are based on the households' incomes in regions or country as a whole), and secondly, methods for constructing isoelastic social welfare functions at the national and regional or zonal levels, which are based on the households' utility functions and include the inequality rejection coefficient. Each value of the coefficient corresponds to a certain concept of social justice. This second group of methods is related to the original approach of the author. The model simulates the development of the government social policy, which is carried out by changing taxes and transfers and taking into account the degree of territorial inequality. Model calculations consider pensions and five types of monetary transfers in a fixed structure: unemployment benefits, child benefits, poverty benefits, social aid and basic income benefits. In a series of experiments, the effect on territorial inequality of changes in the total value of social transfers (with their fixed structure) and tax rates in accordance with the proportionality coefficients was assessed. It is used as a toolkit for changing the system of taxes and transfers and for supporting social policy to reduce spatial inequalities in Russia.
\end{abstract}

Keywords: territorial inequality, social policy, agent-based model, social welfare function.

\section{Introduction}

The aggravation of the problem of social inequality and, above all, territorial inequality has become one of the most significant global challenges of our time $[1,2]$. Inequality is one of the most urgent social problems in Russia [3-5], and it appears especially strongly in the

\footnotetext{
*Corresponding author: tsnovikova@mail.ru
} 
territorial context [6-8]. The leading role in their solution is played by the government [9, $10]$, which is called upon to carry out active social policy in accordance with the new priorities.

To justify public policy focused on solving inequality problems, it is necessary to develop appropriate methods. The aim of the paper is twofold: to develop modeling tools in the avenues of the formal presentation of the principles of social justice with an emphasis on addressing inequality issues, including territorial ones; and to transfer the center for making basic decisions to the micro-level taking into account the increasing complexity of the interaction between agents and a combination of macro-, meso- and microeconomic foundations of social policy with an analysis of structural changes in the economy.

\section{Literature review}

In assessing territorial inequality, ethical considerations come to the force, and the corresponding methods of analysis can be classified according to two main methods of measuring social justice: statistical ones and those constructing a function of social welfare [11]. The concept of social justice in conjunction with economic efficiency, including that used in the analysis of the functions of social welfare, refers to one of the key problems of the economy of the public sector and is constantly discussed in the scientific and educational literature [12-14], frequently in the context of the relationship between inequality and economic growth $[15,16]$. Statistical methods are used in many studies, including assessing territorial inequality both between different countries and within individual nations (for an overview of these studies, see [17-19]). The construction of social welfare functions is less widespread, especially in empirical studies [20-22]. However, in recent decades, there has been a noticeable upsurge in the number of such studies, including those analyzing interregional and intraregional inequality in Russia [23].

Agent-based models (ABMs) have only recently started taking into account the role of government. Initially, these studies focused on monetary and fiscal policy [24], including their interaction with income distribution. The most encouraging results in this area were obtained within a series of related European projects Eurace [25]. Discussion of government intervention is in line with policy analysis in ABMs. As one of the important principles of policy, Leigh Tesfatsion [26] identifies the ability to bridge the gap between conceptual design modeling and real-world design implementation and prescribes the classification the classification of policy models in accordance with policy readiness levels. A separate direction in the study of the reaction of agents to the implemented policy is formed by the tax evasion [27].

In Russia, the leading researchers in this field are the team from the Central Economics and Mathematics Institute headed by Valery Makarov and Albert Bakhtizin [28]. Even in their first works, these authors highlighted inequality in household incomes as one of the most important issues, and later they began to pay considerable attention to the problems of territorial differentiation of economic and social indicators.

The proposed agent-based model was built less than ten years ago on the information and methodological basis of interregional input-output models developed at the Novosibirsk Institute of Economics under the leadership of Aleksandr Granberg, and later Viktor Suslov [29]. The information base of these studies was used in this article along with open sources of statistical data. The government was included in the model later. Agents of federal and regional governments and pension funds were added to households and private firms. The income of these agents of the extended government was formed by indirect (value added tax) and direct taxes (personal income tax and income tax), as well as insurance premiums. In addition, state-owned enterprises producing public goods and selling their products to the respective governments were singled out. Part of the profits that 
remained at the disposal of these enterprises following reimbursement of current expenses and financing of public investments was transferred to the corresponding levels of the budget system. After that, a block of social benefits was developed, including five main (pensions, unemployment, child, poverty benefits and social assistance) and two additional benefits (basic income and quasi benefits) [30,31].

\section{Methods for assessing the social territorial inequality}

The leading part of the proposed set of model tools is a spatial agent-based model (SABM), in which all decisions are made at the microeconomic level of individual agents. The model distinguishes between households, firms, state-owned enterprises, as well as federal and regional governments and the Pension Fund. These decisions, firstly, are aggregated into indicators of the input-output balance table with a transparent representation in the fourth quadrant of the redistributive relationships of all agents. This table also allows one to analyze the scenario conditions of the national and spatial development, taking into account the system of macro-, meso- and intersectoral relationships in the economy as a result of changes in scenario conditions. Secondly, the SBMA solutions are used in the construction of social welfare functions (SWFs) as the basis for social policy at the macroeconomic and regional levels, changing taxes and transfers, thereby establishing a certain institutional framework for agents' decision-making at the microeconomic level. Based on the solutions obtained, a system of economic indicators is calculated, in which social inequality indicators are distinguished and arranged by national, regional and zonal levels. It includes the values of social welfare functions with different coefficients of rejection of inequality, Gini coefficients and macroeconomic indicators of differentiation of GRP, real incomes, wages, and the share of households in final consumption.

The behavior of each household $h(h=1, \ldots, H)$ is modelled by the classical microeconomic approach, according to which decisions are made in accordance with the maximization of the individual utility function for a given budget constraint. Note the following features of the proposed approach. First, households and firms are characterized by spatial coordinates, which is taken into account in transportation assignment to certain regions and zones. The model allows for the following territorial entities: the country as a whole $(r=0)$; regions $(r=1, \ldots, R)$; and zones (Asia, the rest of Russia, $\mathrm{s}=1,2)$. For the quantity of households, the following equations are fulfilled:

$$
H=\sum_{r=1}^{R} H_{r}=\sum_{s=1}^{2} H_{s},
$$

where $h \in H(r), h \in H(s)$ denote household $h$ in territorial unit $r$ or $s$.

Second, households differ in their individual characteristics of the definition of the utility function and the reasons for allocating social transfers. Third, consumer baskets include not only private but also public goods financed from federal or regional budgets. Household maximize the following utility function:

$$
U_{h}\left(x_{1 h}, \ldots, x_{N h}, g\right)=\theta_{h} \cdot \exp \left(\sum_{i=1}^{N} k_{c i h} \ln \left(x_{i h}\right)+k_{g} \ln (g)\right),
$$

where $x_{i h}, g$ are consumption volumes of private and public goods; $\theta_{h}$ is the degree of social insecurity of families with many children and disadvantages.

The functions of public welfare represent a generalization of the concepts of the relationship between economic efficiency and social justice in various territorial entities. The proposed paper uses the classical version of constructing the social welfare functions as functions of individual utilities at the national (3) and regional or zonal levels (4), while applying isoelastic functions depending on the inequality rejection parameter $v$ as follows: 


$$
\begin{aligned}
& F_{0}=\left(\frac{1}{H} \sum_{h=1}^{H} U_{h}^{1-v}\right)^{1 /(1-v)}=\left(\sum_{r=1}^{R} \frac{H_{r}}{H} F_{r}^{1-v}\right)^{1 /(1-v)}=\left(\sum_{s=1}^{2} \frac{H_{s}}{H} F_{s}^{1-v}\right)^{1 /(1-v)} \\
& F_{r}=\left(\frac{1}{H_{r}} \sum_{h \in H(r)} U_{h}^{1-v}\right)^{1 /(1-v)} F_{s}=\left(\frac{1}{H_{s}} \sum_{h \in H(s)} U_{h}^{1-v}\right)^{1 /(1-v)} .
\end{aligned}
$$

An important distinctive feature of social welfare function is the possibility of decomposition in the context of various territorial units.

On the basis of the social welfare function (SWF), the problem of choosing the optimal social policy is investigated by changing tax rates and the shares of social transfers with different ideas about the ratio of efficiency and fairness criteria both at the national level and at the level of regions and groups of regions.

Based on the decisions of the basic ABM, as well as the grouping of indicators in the regional and zonal sections, the Gini coefficients are calculated for various indicators, primarily the total household income and wages. Below are the formulas for calculating the Gini coefficient for household income (which includes social transfers along with wages and property income):

$$
\begin{aligned}
& k_{r}=\sum_{h \in H(r)}\left(2 l_{h}-H_{r}-1\right) I n c_{h} /\left(H_{r} \sum_{h \in H(r)} I n c_{h}\right), r=0, \ldots, R ; \\
& k_{s}=\sum_{h \in H(s)}\left(2 m_{h}-H_{s}-1\right) I n c_{h} /\left(H_{s} \sum_{h \in H(s)} I n c_{h}\right), s=1,2 .
\end{aligned}
$$

where $I n c_{h}$ is income of household $h$ in territorial unit $r$ or $s$, and $l_{h}, m_{h}$ are the rank of this income in ascending order in the territorial unit $r$ or $s$. That is, the lowest income is assigned the rank of 1 , and the highest is assigned the rank of $H_{r}$ or $H_{s}$.

\section{Experimental results}

The considered model toolkit was tested in experimental calculations. Two main series of experiments were carried out: on transfers and on taxes. In the basic version of calculations, the share of transfers in budget revenues was set at $30 \%$, tax rates corresponded to the level of 2015.

In experiments on transfers with a given structure of social transfers, their total value changed in accordance with the coefficients of proportionality. The data from Table 1 generally show how an increase in transfers and a corresponding increase in incomes contribute to the improvement in the position of households: the Gini coefficient decreases slightly, the share of private consumer spending increases markedly, although both the

\begin{tabular}{|c|c|c|c|c|c|c|c|}
\hline \multirow{2}{*}{$\begin{array}{c}\text { Share of } \\
\text { transfers } \\
, \%\end{array}$} & \multicolumn{2}{|c|}{$\begin{array}{l}\text { Final consumption, } \\
\% \text { of GDP }\end{array}$} & \multicolumn{4}{|c|}{$\begin{array}{c}\text { SWF value with inequality rejection } \\
\text { coefficients equal to }\end{array}$} & \multirow{2}{*}{ Gini c. } \\
\hline & $\begin{array}{l}\text { House- } \\
\text { holds }\end{array}$ & $\begin{array}{l}\text { Government final } \\
\text { consumption }\end{array}$ & 0 & 0.5 & 2 & 100 & \\
\hline 15 & 57.50 & 27.90 & 523.8 & 431.4 & 325.2 & 84.6 & 0.397 \\
\hline 30 & 60.60 & 23.60 & 523.4 & 435.1 & 340.7 & 144.3 & 0.380 \\
\hline 45 & 63.70 & 19.20 & 517.7 & 431.1 & 344.6 & 157.5 & 0.377 \\
\hline 60 & 66.60 & 14.70 & 503.2 & 415.5 & 333.3 & 164.3 & 0.384 \\
\hline 75 & 72.40 & 10.40 & 481 & 411.9 & 237 & 174.6 & 0.347 \\
\hline
\end{tabular}
share of government final consumption (respectively, the quantity of public goods) and related public investment decrease.

Table 1. Key indicators in experiments with social transfers. 
However, the expansion of transfers is justifiable to only a certain extent. The right side of Table 1 shows the social welfare function values at four different inequality security ratios. In all cases, as transfers rise, the SWF first rises and then falls. In other words, there is a monotonic dependence of the SWF on the share of transfers in budget revenues with the appearance of local maxima. The corresponding values of the specific weights, and hence the scale of the redistributive social policy, can be considered as optimal. For example, with utilitarian ideas about social justice corresponding to $v=0$, the reduction of social transfers payments to a $15 \%$ level is optimal; with their increase, the SWF decreases. On the contrary, with an unusually high level of $v=100$ corresponding to the Rowlsian choice, the maximum arises with the overwhelming part of budget revenues allocated to finance social transfer payments (in the amount of 75\%). The level of well-being measured by the SWF value decreases compared to the utilitarian maximum by a factor of 3.0 (from 523.8 to 174.6 units). More realistic ideas about the choice between efficiency and equity correspond to the level of $v$ between 0.5 and 2, presented in the intermediate columns of Table 1 with the optimal SWF values of 435.1 and 344.6 units and the corresponding optimal transfer weights of $30 \%$ and $45 \%$.

Experiments with transfers have revealed another important feature. The optimal social welfare function values form a monotonically decreasing curve, which can be called isooptimal and considered as the basis for choosing optimal decisions in social policy.

Another series of experiments simulates the impact of changes in tax burden in accordance with proportionality coefficients for the existing rates of personal income tax, VAT and income tax. The results of these calculations are presented in Table 2. As seen from the data, the increase in taxation leads to a significant decrease in the Gini coefficient. It is associated with an increase in public goods production and the corresponding proportion of government final consumption in final use, together with an increase in transfers. At the same time, in household consumption, private goods are replaced with public goods accompanied by a decrease in private consumer spending in final consumption.

Table 2. Key indicators in experiments with taxes.

\begin{tabular}{|c|c|c|c|c|c|c|c|c|}
\hline \multirow{2}{*}{$\begin{array}{c}\text { Proporti } \\
\text { onality } \\
\text { factor }\end{array}$} & \multicolumn{3}{|c|}{ Macro indicators, \% } & \multicolumn{3}{c|}{$\begin{array}{c}\text { SWF value with inequality } \\
\text { rejection coefficients equal to }\end{array}$} & \\
\cline { 2 - 10 } & Housholds & $\begin{array}{c}\text { Government } \\
\text { final } \\
\text { consumption }\end{array}$ & Transfers & $\mathbf{0}$ & $\mathbf{0 . 5}$ & $\mathbf{2}$ & $\mathbf{1 0 0}$ & \\
\hline 0.5 & 67.3 & 14.1 & 4.6 & 513.2 & 396.0 & 279.0 & 72.8 & 0.461 \\
\hline 1 & 60.6 & 23.6 & 9.2 & 523.4 & 435.1 & 340.5 & 144.3 & 0.380 \\
\hline 2 & 52.5 & 30.9 & 13.4 & 511.0 & 448.2 & 372.2 & 172.1 & 0.313 \\
\hline 3 & 47.0 & 36.8 & 17.6 & 492.2 & 449.0 & 391.7 & 188.7 & 0.260 \\
\hline 4 & 41.8 & 45.7 & 25.6 & 462.1 & 440.9 & 402.8 & 215.3 & 0.196 \\
\hline
\end{tabular}

Calculations with taxes for social welfare function show trends similar to experiments with transfers. For each given coefficient of rejection of inequality, an increase in the tax burden first leads to an increase and then to a decrease in the SWF, a local maximum arises, and a set of local maxima forms an iso-optimal decreasing line.

\section{Conclusions}

The presented approach to the analysis of social policy with an emphasis on solving the problems of territorial inequality offers many possibilities for studying the territorial 
development of the Russian economy based on the use of a combination of agent-oriented and input-output modeling with the construction of social welfare functions:

1. Formalization of the relationship between social justice and economic efficiency due to social welfare function both at the national level and at the level of regions and their groups in combination with the calculation of Gini coefficients for total income and wages provides an effective toolkit for assessing the level of territorial inequality and choosing optimal solutions for justification social policy;

2. Input-output table creates the basis for analyzing the differentiation of macro- and mesoeconomic indicators, as well as the main structural changes in the economy in the implementation of social policy, including a visual representation in the fourth quadrant of redistribution processes when taxes and transfers change;

3. The dependence of social welfare on the scale of redistribution shows that for each coefficient of rejection of inequality in experiments with both transfers and taxes, local SWF maxima arise, which form monotonically decreasing iso-optimal curves and create the basis for choosing optimal social policy.

Acknowledgements: This research was funded by the Russian Foundation for Basic Research, project No. 20-010-00377.

\section{References}

1. J. Stiglitz, J. Fitoussi and M. Durand, Beyond GDP: Measuring What Counts for Economic and Social Performance, Ch.2. (OECD, 2018)

2. T. Piketty, Capital in the 21st century (Harvard University Press, 2014)

3. F. Novokmet, T. Piketty, G. Zucman, J. Ec. Inequality, 16, 189 (2018)

4. A. Aganbegyan, On priorities of social politics (Delo, Moscow, 2018)

5. E. Varshavsky, Sociological studies, 8, 52 (2019)

6. Rolling back Russia's spatial disparities (WBR, World Bank Group, 2018)

7. N. Zubarevich, Soc. Sc. Cont. World, 4, 57 (2019)

8. M. Y. Malkina, Terra Economicus, 18 (3), 140 (2020)

9. J. Ocampo, J. Stiglitz (Eds.), The Welfare State Revisited (CUP, 2018)

10. J. Stiglitz, People, Power, and Profits (W. W. Norton \& Company, 2019)

11. A. B. Atkinson, F. Bourguignon (Eds.), Handbook of income distribution (Amsterdam, NH, 2015)

12. Inequality concepts and theories in the postcrisis Europe. Summary of the literature review, UPLIFT, 870898 (2020)

13. S. R. Chakravart, Analyzing multidimensional well-being: A quantitative approach (J. Wiley \& Co., 2018)

14. Y. Davydov, F. Greselin, Econometrics J., 22 (2), 153 (2019)

15. K. J. Forbes, Am. Ec. Review, 90 (4), 869 (2000)

16. A. Berg et al., J. Ec. Growth, 23 (3), 259 (2018)

17. C. I. Jones, P. J. Klenow, Am. Ec. Review, 106(9), 2426 (2016)

18. J. R. Rosés, N. Wolf, CEPR Disc. Paper 12749 (2018)

19. K. P. Gluschenko, St. Rus. Ec. Dev., 13 (1), 78 (2018)

20. M. Y. Malkina, Terra Economicus, 14 (3), 29 (2016)

21. M. Luptasik., E.Nejinsky, C. E. J. Oper. Res., 28, 561 (2020) 
22. N. Sakamoto, Y. Mori, RCNE Disc. Paper, 8 (2020)

23. A. A. Kuklin, I. V. Korobkov, Econ. of Region, 14 (4), 1145 (2018)

24. G. Dosi, M.C. Pereira, A. Roventini, M.E. Virgillito, J. Ec. Beh. \& Organization, 162(C), 360 (2019)

25. H. Dawid, D. Gatti, WP in Ec. Man., 2, 1 (2018)

26. L. Tesfatsion, Ch. 13 in Handb. of CE4: Heterogeneous Agent Models, Amsterdam, 715 (2018)

27. S. Hokamp, L. Gulyás, M. Koehler, S. Wijesinghe, ABM of tax evasion (Wiley, 2018)

28. V. L. Makarov, A. R. Bakhtizin, E. D. Sushko, J. New Econ. Assoc., 45 (1), 151 (2020)

29. A. G. Granberg, V. I. Suslov, S. A. Suspitsyn, Multiregional systems: economic and mathematical research. (Sib. Scient. PH, Novosibirsk, 2007)

30. T. S. Novikova, A. A.Tsyplakov, Economic and Social Changes: Facts, Trends, Forecast, 13, 129 (2020)

31. T.S. Novikova, A.A.Tsyplakov, J. New Econ. Assoc., 52 (4) (to be published) (2021) 